\title{
Factors related to failure to attend the consultation to receive the results of the Pap smear test ${ }^{1}$
}

\author{
Camila Teixeira Moreira Vasconcelos ${ }^{2}$ \\ Denise de Fátima Fernandes Cunha ${ }^{3}$ \\ Cássia Fernandes Coelho ${ }^{4}$ \\ Ana Karina Bezerra Pinheiro² \\ Namie Okino Sawada ${ }^{5}$
}

Objective: to identify the factors related to the failure of women to attend the follow-up consultation to receive the results of the Pap smear test. Method: a cross-sectional study, carried out with 775 patients who underwent the Pap smear test in the Centro de Saúde da Família of Fortaleza, between September 2010 and February 2011. Results: the majority of the women studied were young ( $\leq 35$ years), had low levels of education ( $\leq 7$ years of study), and commenced sexual activity early ( $\leq 20$ years), with $17.0 \%$ of them failing to return to receive the test results. Statistically significant results for the failure to return were related to: young women $(p=0.001)$; early onset of sexual activity $(p=0.047)$; and inadequate knowledge about the Pap smear test $(p=0.029)$. Conclusion the fact that the women failed to return for the result is a problem for the control of cervical cancer and must be addressed through educational strategies that reinforce the importance of the return for the early detection of this cancer.

Descriptors: Health Knowledge, Attitudes, Practice; Vaginal Smears; Uterine Cervical Neoplasms; Nursing.

\footnotetext{
${ }^{1}$ Paper extracted from doctoral dissertation "Intervenção comportamental e educativa: efeitos na adesão das mulheres à consulta de retorno para receber o resultado do exame colpocitológico", presented to Departamento de Enfermagem, Faculdade de Farmácia, Odontologia e Enfermagem, Universidade Federal do Ceará, Fortaleza, CE, Brazil.

${ }^{2}$ PhD, Adjunct Professor, Departamento de Enfermagem, Faculdade de Farmácia, Odontologia e Enfermagem, Universidade Federal do Ceará, Fortaleza, CE, Brazil.

${ }^{3}$ Master's student, Departamento de Enfermagem, Faculdade de Farmácia, Odontologia e Enfermagem, Universidade Federal do Ceará, Fortaleza, CE, Brazil.

${ }^{4} \mathrm{RN}$.

${ }^{5} \mathrm{PhD}$, Associate Professor, Escola de Enfermagem de Ribeirão Preto, Universidade de São Paulo, WHO Collaborating Centre for Nursing Research Development, Ribeirão Preto, SP, Brazil.
}

Corresponding Author:

Camila Teixeira Moreira Vasconcelos

Universidade Federal do Ceará.

Faculdade de Farmácia, Odontologia e Enfermagem

Departamento de Enfermagem

Rua Alexandre Baraúna, 949

Bairro: Rodolfo Teófilo

CEP: 60430-160, Fortaleza, CE, Brasil

E-mail: camilamoreiravasco@gmail.com

Copyright (c) 2014 Revista Latino-Americana de Enfermagem This is an Open Access article distributed under the terms of the Creative Commons Attribution Non-Commercial License (CC BY-NC).

This license lets others distribute, remix, tweak, and build upon your work non-commercially, and although their new works must also acknowledge you and be non-commercial, they don't have to license their derivative works on the same terms. 


\section{Introduction}

Despite showing high cure potential when diagnosed early, cervical cancer (CC) still remains a serious public health problem, especially in developing countries, where screening tests are conducted opportunistically, and for women below the age group at risk for this cancer ${ }^{(1)}$. The incidence and mortality resulting from $\mathrm{CC}$ can be reduced through screening for the detection and treatment of invasive cancer precursor lesions. According to the World Health Organization (WHO), with Pap smear test coverage of between 80 and $100 \%$ of the target population and an organized network for adequate diagnosis and treatment, it is possible to reduce the cases of invasive cancer in the population by an average of 60 to $90 \%{ }^{(2)}$. However, a recent study revealed that the provision of the test in Brazil is still found to be below the requirements of Brazilian women(3).

Numerous interventions to improve the adherence of women to the Pap smear test have been described in the literature. These interventions focus on improving the information provided by the professionals about the exam, reducing the barriers for the women to have access to the exam, or both ${ }^{(4-5)}$. Despite the magnitude of these interventions, the high cure potential for $\mathrm{CC}$, and the increase in the provision of services for prevention and treatment of the cases, the control of this condition will be limited if these women do not return to receive the test results(6).

This situation is complex, because a financial and professional investment is made by the service with each examination performed, however, the ultimate impact is impaired. Graduate and technical professionals are involved, as well as various expenses, in the sample collection process, reading the slide, and printing the result. When a woman does not return to the service to receive this result, there is a waste of time and resources, both for the service provider and for the woman, because the purpose of the examination, i.e. the prevention of cervical cancer, is not achieved(6).

Some studies ${ }^{(6-8)}$ have already addressed the issue of women failing to return for the Pap smear test result, however, they are characterized as descriptive studies that only aimed to discover the reasons why the women failed to return and to identify their characteristic profile, without establishing any statistical relationship between the variables. Furthermore, another factor that prompted the realization of this study was the finding, in a preliminary study performed in a primary health unit (PHU) of Fortaleza, of a high rate $(24 \%)$ of
Pap smear tests not received by the users ${ }^{(6)}$.Thus, the following question arose: what factors are related to the failure of women to return to receive the result of the Pap smear test?

The identification of the profile of the women who fail to return may support the development of interventions, with emphasis on cognitive, behavioral and social aspects, by the primary healthcare professionals to improve the quality of the care provided to combat $\mathrm{CC}$.

\section{Method}

This was a cross-sectional study carried out in a Family Health Center (CESAF) of Fortaleza, composed of four teams. In this institution the tests are performed exclusively by nurses, in four periods per week, with ten women attended per period. This institution was selected because, in a previous study, it presented a rate of approximately $24 \%$ of exams that were not received by the women. One hypothesis for the high number of retained tests is that, in the unit, the followup consultation was not scheduled. Furthermore, despite making use of an active search, a significant percentage of exams were not getting into the hands of the women(6).

The study population was composed of women who sought the performance of the examination in this institution. The sample size was calculated using a confidence interval of $95 \%$, power of $80 \%$, and a percentage of eventual losses of $10 \%$, amounting to a total of 699 women. The sample included only the women who had commenced sexual activity; excluding those who, for any reason, left the unit without performing the Pap smear test.

As the data were collected while the women waited to perform the test, only later was it realized that some of the women who had been interviewed left the office without carrying out the examination, which determined their exclusion. Thus, it was decided to expand the sample beyond the estimated 699 women, in order to ensure that, if it was necessary to exclude anyone, this value would be obtained. Therefore, at the end of the study, a sample of 775 women was achieved.

Identification data were collected for all the women who agreed to participate in the study and a validated instrument, called a KAP survey, was applied to assess their knowledge, attitude and practice in relation to the Pap smear test. The reason for the application of the KAP survey was the fact that it makes it possible to measure what the population knows and how it thinks and acts 
faced with a particular problem, in the case of this study, the Pap smear test ${ }^{(9)}$. The criteria described below were used to assess the knowledge, attitude and practice ${ }^{(10)}$ :

- Adequate knowledge: when the woman reported that she had heard about the test, she knew it was to detect cancer in general, or specifically cervical cancer, and was able to cite at least two steps required prior to performing the test.

- Inadequate knowledge: when the woman reported having never heard of the test or had heard of it, but did not know it was to detect cancer, or when she was not able to cite at least two steps required prior to performing the test.

- Adequate attitude: when the woman presented the prevention of cervical cancer as the reason for performing the Pap smear test. When the woman stated the fact that it is a routine examination or referred to the wish to know whether all was well with her as the reason, this was only considered an appropriate attitude when, simultaneously, she had adequate knowledge about the test.

- Inadequate attitude: when the woman presented reasons for the performance of the exam other than the prevention of CC.

- Adequate practice: when the woman had performed her last Pap smear test, at most, within the previous three years; had returned to receive the latest test result, and sought an appointment to discuss the results of the test;

- Inadequate practice: when the woman had performed the last preventive examination over three years before or had never performed the test, even having initiated sexual activity for more than one year; or when she had not returned to receive the last result; or not sought an appointment to show the test result.

The last data collection phase took place on the day of the follow-up consultation, in which the data related to the attendance of the woman (number of days between the exam and return) and the test results were recorded. It is important to note that in this service, despite being necessary, the patient does not leave with a follow-up consultation scheduled, which makes it difficult to analyze the factors related to the failure to return.

In order to ensure the right to a follow-up consultation for the women, all the study participants had followup consultations scheduled with the researcher within a period of around 45 days (Md: $43 \pm 5.6$ days/Min:30 days/Max:54 days) after the date of the examination, which should exist in every service that performs the
CC prevention test. This period for scheduling the return varied due the fact that some months had more holidays than others, hindering the scheduling of consultations with shorter intervals.

All the patients were informed that if they could not attend on the scheduled date (usually on Thursdays), they could return on any subsequent Thursday, or even on one of the days when the Pap smear test was carried out in the unit (Mondays, Tuesdays, Wednesdays and Fridays).

The period for the collection of the KAP survey was between September 2010 and February 2011, giving a total of six months. However, due to the followup consultation extending up to 60 days after the performance of the test, the total collection period took place until mid-May 2011 (approximately nine months).

The data were compiled and analyzed using the Statistical Package for the Social Sciences ${ }^{\circledR}$ (SPSS) version 18.0. The continuous variables were expressed as mean \pm standard deviation with the confidence interval (CI) of $95 \%$ and the categorical variables as frequencies and percentages. To evaluate the existence of factors related to the failure of the women to attend the follow-up consultation, to receive the result of the Pap smear test, Pearson's chi-square test was used. For all the analyzes, a value of $p<0.05$ was considered statistically significant.

Compliance with the standards for research with human subjects was assured, according to Resolution $196 / 96$ of the National Health Council of Brazil(11). The project was submitted to the Research Ethics Committee (CEP) of the Federal University of Ceará and approved with the protocol number $81 / 09$.

\section{Results}

Throughout the study 802 questionnaires were completed, however, 27 women were excluded from the sample because they did not performed the Pap smear, which provided a sample of 775 patients. The age of the women studied ranged from 13 to 78 years, with a mean of 35 years. They had, on average, completed seven years of study and had initiated sexual activity (ISA) at around 16 years of age. The majority of the women that performed the test during the study were less than 35 years of age $(58.5 \%)$, lived with a partner $(69.4 \%)$, did not work outside the home $(62.3 \%)$, and lived near the clinic (94.2\%). There was a high percentage of inadequacy regarding knowledge about the test $(72.3 \%)$. 
All the participants scheduled follow-up consultations with a mean interval of 43 days (Minimum: 30 days/Maximum: 54 days) after the performance of the test. When leaving the unit, all the patients received a visual reminder, with information about the date, time and the name of the professional responsible for the follow-up consultation. If the women could not attend on the scheduled day, there was the possibility of receiving the result at a later date, until the completion of the study (May 2011).

During the study period, of the 775 women in the sample, the majority ( $83 \%$ ) attended to receive the test results, although $28 \%(n=181)$ of these came after the date scheduled for the return (Figure 1 ).

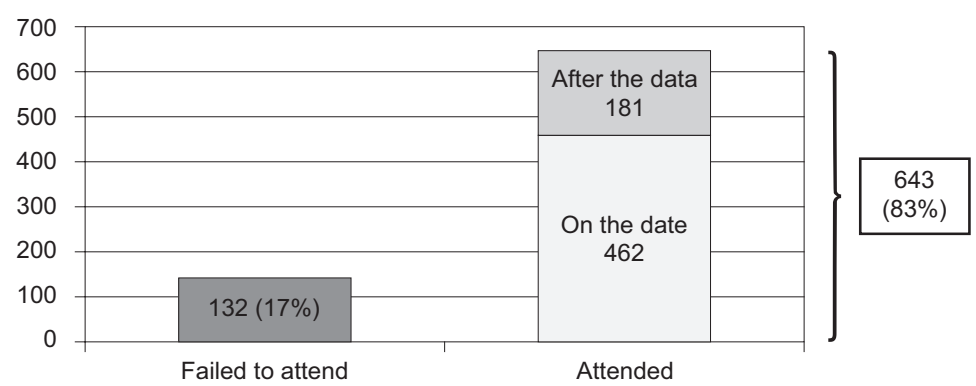

Figure 1 - Distribution of the sample according to attendance of the follow-up consultation. Fortaleza, CE, Brazil 2011

The median number of days for the 643 patients to return to receive the result of the test was 45 ( \pm 23 ) days, with the interval varying from 30 to 287 days. Among the main reasons for attending after the scheduled date, personal reasons were highlighted, comprising $91.6 \%$ of the justifications. Personal reasons are classified as situations where something related to the woman herself (disease, forgetfulness, problems at home, work, travel, etc.) prevented her from collecting the test results.

Of all the women who failed to return, eight (17\%) presented unsatisfactory samples, four (8.9\%) exhibited accentuated inflammation and one (2.2\%) purulent inflammation. The test result of one woman (2.2\%) was compatible with Cervical Intraepithelial Neoplasia I (CIN I) and of three (6.7\%) with Atypical Squamous Cells of Undetermined Significance (ASCUS).

Although all the women who attended the study unit after the scheduled date received their results, for the calculation of the factors related to failure to attend the follow-up consultation it was necessary to define the interval limit of sixty-five days to consider that the woman had returned. This deadline was adopted because it was the maximum number of days given for the last patient that underwent the test to return. That is, the women who attended within sixty-five days to receive the test results were classified as "Returned", the women who attended after sixty-five days from the performance of the examination and those who did not attend were classified as "Failed to return". Thus, with 132 women who did not attend and 58 who attended after 65 days, a total of 190 women was obtained.

Higher proportions of non-attendance of the followup consultation were found to be related to the following characteristics: young women $(p=0.001)$; early initiation of sexual activity ( $p=0.047)$, and women classified in the KAP survey as having inadequate knowledge about the Pap smear test $(p=0.029)$. The fact that the woman did not live near to the clinic had no statistical significance with failure to return (Table 1 ).

Something which also needs to be clear: "Early onset of sexual activity" was defined as $\leq 20$ years, based on what? The age defined as the limit of adolescence? Based on which reference?

Table 1 - Factors related to the failure of women to attend the follow-up consultation. Fortaleza, CE, Brazil 2011

\begin{tabular}{|c|c|c|c|c|c|}
\hline \multirow[t]{2}{*}{ Variables $(n=775)$} & \multicolumn{2}{|c|}{$\begin{array}{l}\text { Failed to return } \\
(\text { Total }=190)\end{array}$} & \multirow[t]{2}{*}{$x^{2}$} & \multirow[t]{2}{*}{$\mathbf{P}$} & \multirow[t]{2}{*}{ OR $(95 \% \mathrm{Cl})$} \\
\hline & $\mathbf{N}$ & $\%$ & & & \\
\hline Age & & & 11.695 & 0.001 & $1.8(1.2-2.6)$ \\
\hline$\leq 35$ years $(n=469)$ & 135 & 28.8 & & & \\
\hline$>35$ years $(n=306)$ & 55 & 18.0 & & & \\
\hline
\end{tabular}


Table 1 - (continuation)

\begin{tabular}{|c|c|c|c|c|c|}
\hline \multirow[t]{2}{*}{ Variables $(n=775)$} & \multicolumn{2}{|c|}{$\begin{array}{l}\text { Failed to return } \\
(\text { Total=190) }\end{array}$} & \multirow[t]{2}{*}{$x^{2}$} & \multirow[t]{2}{*}{$\mathbf{P}$} & \multirow[t]{2}{*}{ OR $(95 \% \mathrm{Cl})$} \\
\hline & $\mathbf{N}$ & $\%$ & & & \\
\hline Education & & & 0.773 & 0.379 & $0.8(0.6-1.1)$ \\
\hline$\leq 9$ years $(n=413)$ & 96 & 23.2 & & & \\
\hline$>9$ years $(n=362)$ & 94 & 26.0 & & & \\
\hline Initiation of sexual activity & & & 3.963 & 0.047 & $1.7(1.0-3.1)$ \\
\hline$\leq 20$ years $(n=680)$ & 174 & 25.6 & & & \\
\hline$>20$ years $(n=93)$ & 15 & 16.1 & & & \\
\hline Marital status & & & 0.026 & 0.871 & $1.0(0.7-1.4)$ \\
\hline Single $(n=237)$ & 59 & 24.9 & & & \\
\hline With a partner $(n=538)$ & 131 & 24.3 & & & \\
\hline \multicolumn{6}{|l|}{ Working outside the home } \\
\hline Yes $(n=292)$ & 82 & 28.1 & 3.220 & 0.073 & $1.3(0.9-1.8)$ \\
\hline No $(n=483)$ & 108 & 22.4 & & & \\
\hline Live near & & & 1.123 & 289.000 & $0.7(0.3-1.3)$ \\
\hline Yes $(n=730)$ & 176 & 24.1 & & & \\
\hline No $(n=45)$ & 14 & 31.1 & & & \\
\hline Performance of the exam & & & 3.197 & 0.074 & $1.5(0.9-2.6)$ \\
\hline First time $(n=76)$ & 25 & 32.9 & & & \\
\hline Subsequent $(n=699)$ & 165 & 23.6 & & & \\
\hline Knowledge & & & 4.769 & 0.029 & $1.5(1.0-2.2)$ \\
\hline Inadequate $(n=560)$ & 149 & 26.6 & & & \\
\hline Adequate $(n=215)$ & 41 & 19.1 & & & \\
\hline Attitude & & & 2.783 & 0.095 & $0.7(0.5-1.0)$ \\
\hline Inadequate $(n=491)$ & 130 & 26.5 & & & \\
\hline Adequate $(n=284)$ & 60 & 21.1 & & & \\
\hline Practice & & & 0.005 & 0.941 & $0.9(0.6-1.4)$ \\
\hline Inadequate $(n=239)$ & 59 & 24.7 & & & \\
\hline Adequate $(n=536)$ & 131 & 24.4 & & & \\
\hline
\end{tabular}

\section{Discussion}

Compared with the non-return rate of $24.9 \%$ found in 2008 in the same health unit(6), this study confirmed that there was a reduction to $17 \%$. This fact can be attributed to the guarantee of a scheduled follow-up consultation for all patients, which did not previously exist in the unit studied. In addition to scheduling, there was flexibility in attending the women who for some reason could not attend on the scheduled date, which enabled the return of 181 more women to receive the test results.

In a study conducted in Fortaleza, of the 645 women who performed the examination in 2005 to June 2006, 101 (15.6\%) failed to return to receive the test results ${ }^{(7)}$. During the household survey conducted in Pelotas, Rio Grande do Sul, in the period October to December 2003, with 1,404 women, the result of the last examination was not at that time known by $10.3 \%$ of the women irrespective of time of performance, with $8.1 \%$ in the public services, and $3.2 \%$ in the health insurance or private services ${ }^{(12)}$. Among the studies in which the percentage of non-returns has been studied, the rates are much lower than that found in this study, however, the methodology used makes comparisons difficult.

A study carried out in a primary health unit in Fortaleza revealed that the factors that hinder women's access to the test results originate from questions linked to the organization of the healthcare service and from issues related to the woman herself. The former being responsible for a far greater share (27.3\%) compared to the others ${ }^{(7)}$.

It is noteworthy that the women's apparent lack of interest in receiving the results, represented by the justifications for personal reasons, is not always unilateral $^{(7)}$. The low quality of the care provided, the difficulty in arranging a new consultation when the woman can not attend on the scheduled date, the long waiting list for service or to schedule a consultation, and the lack of effective communication between the user and service professionals also contribute to hinder women's access to the test results( ${ }^{(6-7)}$, 
The problem of failing to return is present in various contexts, although in varying proportions, indicating the need for the healthcare professionals responsible for CC prevention to use cognitive type strategies to increase women's knowledge related to the fight against cervical cancer, emphasizing the importance of the return consultation. Behavioral type strategies should also be used to reinforce the behavior of returning, using reminders (graphics, visual or telephone calls), as well as social strategies, which might include changes in the current healthcare system in order to optimize the dynamics of the care with the aim of reducing these numbers. Therefore, it is necessary not only to know the reasons why women fail to return, but also who these women are and whether there are characteristics related to the non-return behavior.

In a study also performed in Fortaleza, in order to assess the knowledge, attitudes and practices of 250 women regarding the Pap smear test, it was found that $67.6 \%$ of the respondents were classified as having inadequate practice concerning the test. The women who reported performing the exam at intervals of more than three years showed higher proportions of failure to return for the result of the last examination ${ }^{(10)}$.

In this study, age was the factor most strongly associated with failure to return $(O R=1.8)$. Despite the younger women ( $<35$ years) performing the examination more often, even if not in the age group at greatest risk from cervical cancer, they were the least likely to return for the result of the Pap smear test, as verified in the present study (mean age of the women who returned $=37.0 /$ mean age of women who failed to return $=31.0: p=0.001$ ). This may be one of the factors that contribute to the low impact of the examination on the indices of mortality from CC. Furthermore, it is noteworthy that women who present one of the risk factors for cervical cancer, which is the early initiation of sexual activity, are 1.7 times more likely to fail to return for the result (Table 1 ).

Although low levels of education were not statistically associated with failure to return (mean years of schooling of the women who returned=7.0/ mean years of schooling of the women who failed to return $=7.2: p=0.888$ ), another study ${ }^{(12)}$ demonstrated that the percentage of women who did not know the result of their examinations increased with decreased schooling: the proportion was approximately three times greater among those with less than four years of schooling compared to women with twelve or more years of education (10.7\% versus $2.9 \%$ ) (linear trend $p$ value $=0.000)$. Just over a third $(35.6 \%)$ of the women with up to four years of schooling believed that CC is incurable, while among the women with twelve or more years of education, the percentage was $9.9 \%{ }^{(12)}$.

Inadequate knowledge regarding the Pap smear test is described in the literature ${ }^{(10)}$ as a risk characteristic for not performing the examination and, in this study, for failing to return. These data show that gaps in knowledge influence the adoption of healthy behaviors, especially, in the case of this study, regarding the attitude of the women related to returning for the result.

In this sense, it is necessary to apply a health education strategy, which should be performed by a multidisciplinary team of healthcare professionals, especially nurses. To adequately fulfill the role of educator, the professional should identify the information that the learners need and consider their motivations and learning styles. However, to only provide information to the learners does not guarantee their learning(13). Learning needs are defined as gaps in knowledge between the actual performance level and desired performance level. Such gaps exist due to lack of knowledge, attitude or ability.

It is important to note that not all the individuals perceived their own need to obtain knowledge about a particular subject. Therefore, it is up to the educator to help them identify, clarify and prioritize their needs and interests. After this, the information gathered could, in turn, be used to establish goals and plan appropriate and effective approaches in the teaching-learning process so that the education begins at an appropriate point for the learner, and not from a unknown or inappropriate level(13).

Despite all the dangers posed by the woman failing to return, highlighted in this article, it can still be perceived that, although in a reduced quantity, women who present unsatisfactory samples are not being advised to immediately repeat the tests. Furthermore, those showing an accentuated or purulent inflammation process cannot be treated, and those showing cellular changes cannot be monitored properly. Although, in such cases, nurses can make use of an active search, this does not guarantee success. Situations such as this adversely affect the integrality of the care provided and contribute to make early detection of CC difficult.

\section{Conclusions}

There are several intervention needs in the combat against $\mathrm{CC}$, however, adequate knowledge regarding the 
test (purpose, necessary care, periodicity) and regarding the importance of a return visit should be the target of these interventions, aiming to enable women to choose healthier behaviors and improve their quality of life.

As contributions for improving care to the woman, this study primarily alerts the healthcare team, especially nurses working in the CC screening programs, about the problem of failure to return. It suggests the organization of the care and the guarantee of a followup consultation, as well as the development of routine and effective educational interventions, with attractive strategies, especially for younger women and those with low education. With this, it would be possible to reduce the number of women who fail to return to receive the results of the test, as well as to encourage the regular performance of this procedure among the users of the service. Studies that test the efficacy of these interventions should also be performed.

\section{References}

1. Instituto Nacional do Câncer (Brasil), Coordenação Geral de Ações Estratégicas, Divisão de Apoio à Rede de Atenção Oncológica. Diretrizes brasileiras para o rastreamento do câncer do colo do útero. Rio de Janeiro: INCA; 2011.

2. World Health Organization. International Agency for Research on Cancer.World CancerReport 2008. Lyon: IARC; 2008.

3. Dias MBK, Tomazelli JG, Assis M. Rastreamento do câncer de colo do útero no Brasil: análise de dados do Siscolo no período de 2002 a 2006. Epidemiol Serv Saúde. 2010;19(3):293-306.

4. Vasconcelos CTM, Damasceno MMC, Lima FET, Pinheiro AKB. Revisão integrativa das intervenções de enfermagem utilizadas para detecção precoce do câncer cérvico-uterino. Rev. Latino-Am. Enfermagem. 2011;19(2):437-44.

5. Gamarra CJ, Paz EPA, Griep RH.Social support and cervical and breast cancer screening in Argentinean women from a rural population. Public Health Nurs. 2009;26(3):269-76.

6. Vasconcelos CTM, Vasconcelos Neto JA, Castelo ARP, Medeiros FC, Pinheiro AKB. Analysis of coverage and of the pap test exams not retired of a basic health unit. Ver Esc Enferm USP. 2010;44(2):324-30.

7. Gomes LM, Pinheiro AKB, Vasconcelos CTM, Falcão JSP Júnior. Exame de Papanicolaou: fatores que influenciam as mulheres a não receberem o resultado. Enferm Global. 2010;9(3):1-11.
8. França FMSG, Gonçalves MTAM. Atuação do enfermeiro no incentivo ao retorno das mulheres para buscar o resultado de colpocitologia oncótica. Anuário Produção de Iniciação Científica Discente. 2007;10(11):33-9.

9.Kaliyaperumal K. Guideline for conducting a knowledge, attitude and practice (KAP) study. AECS Illumination. 2004;4(1):7-9.

10. Vasconcelos C, Pinheiro A, Castelo ARP, Costa LQ, Oliveira RG. Knowledge, attitude and practice related to the Pap smear test among users of a primary health unit. Rev. Latino-Am. Enfermagem. 2011;19(1):97-105.

11.Conselho Nacional de Saúde (BR). Resolução no 196/96. Decreto n 93.933 de Janeiro de 1987. Estabelece critérios sobre pesquisa envolvendo seres humanos. Bioética. 1996;4(2 Supl):15-25.

12. Hackenhaar AA, César JA, Domingues MR. Exame citopatológico de colo uterino em mulheres com idade entre 20 e 59 anos em Pelotas, RS: prevalência, foco e fatores associados à sua não realização. Rev Bras Epidemiol. 2006;9(1):103-11.

13. Bastable SB. O enfermeiro como educador: princípios de ensino-aprendizagem para a prática de enfermagem. $3^{a}$ ed. Porto Alegre: Artmed; 2010.
Received: Feb. $4^{\text {th }} 2013$ Accepted: Dec. $5^{\text {th }} 2013$ 